\title{
Sarcoidotic Truncal Neuropathy
}

Key words: sarcoidosis, truncal neuropathy
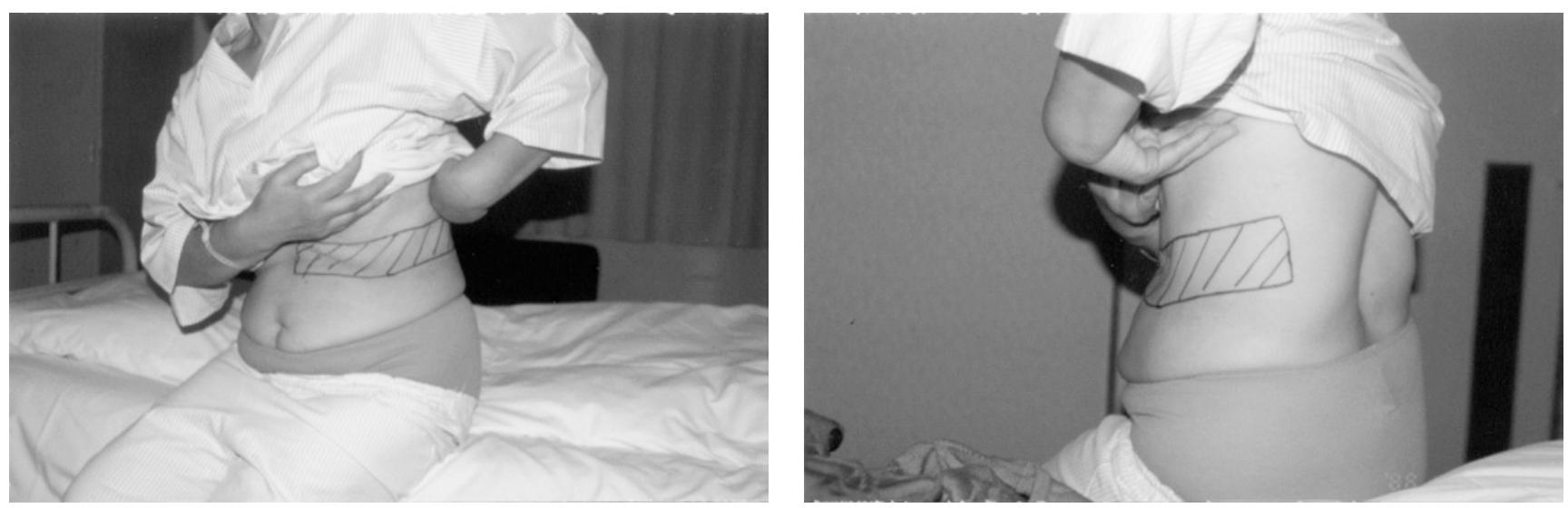

Figure 1. Distribution of the belt-like hypesthesia and hypalgesia of the left trunk with preservation of the median region of the front and back.

A 64-year-old female was admitted to the hospital due to a 3-week history of hypesthesia of the left abdomen and right facial palsy. She had no history of diabetes. Neurological examination showed right peripheral facial palsy and belt-like hypesthesia and hypalgesia of the left trunk with preservation of the median region of the front and back, similar to diabetic truncal neuropathy $(1,2)$. Angiotensin-converting enzyme was $29.8 \mathrm{IU} / \mathrm{l}$, blood glucose was $102 \mathrm{mg} / \mathrm{dl}$, chest Xp and CT showed bilateral hilar lymph node swelling, Ga scintigraphy showed accumulation in the hilar and mediastinal lymph nodes, bilateral lacrimal glands and parotid glands. Bronchoalveolar lavage fluid showed 48\% lymphocytes, 50\% histiocytes, $\mathrm{CD} 4 / \mathrm{CD} 8=12.7$. Tuberculin test was negative and enhanced magnetic resonance imaging of the spinal cord was negative. Diabetic truncal neuropathy is well known but there is no report of truncal neuropathy due to sarcoidosis. We think sarcoidosis may have caused truncal neuropathy as the initial symptom.

\section{References}

1) Stewart JD. Diabetic truncal neuropathy: topography of the sensory deficit. Ann Neurol 25: 233-238, 1989.

2) Waxman S, Sabin TD. Diabetic truncal neuropathy. Arch Neurol 38: 46-47, 1981.

\section{Naoki KASAHATA****, Kazuki HANAUE* and Tetsumasa KAMEI*}

From *the Department of Neurology, Chigasaki Tokushukai General Hospital, Chigasaki

and **Department of Laboratory Medicine, Musashi Hospital, National Center for Neurology and Psychiatry

Received for publication January 6, 2005; Accepted for publication January 24, 2005

Reprint Requests should be addressed to Dr. Naoki Kasahata, the Department of Laboratory Medicine, Musashi Hospital,

National Center for Neurology and Psychiatry, 4-1-1 Ogawahigashimachi, Kodaira, Tokyo 187-8502 